\title{
Etiological Profile and Management of Epistaxis in Tertiary Care Hospital
}

\author{
Sigdel $B^{1 *}$, Nepali $R^{1}$, KC Neeraj ${ }^{2}$, Dubey $T^{3}$, Neupane $B^{4}$, Sigdel $D^{5}$ \\ ${ }^{1}$ Associate Professor, ${ }^{2}$ Assistant Professor, ${ }^{3}$ Lecturer, Department of ENT, \\ Gandaki Medical College \& Teaching Hospital, Pokhara, Nepal \\ ${ }^{4}$ Lecturer, Department of Anatomy, Manipal College of Medical Sciences, Pokhara, Nepal \\ ${ }^{5}$ Research Assistant, Faculty of Health Sciences, Ehealth, McMaster University, 1280 Main Street West, \\ Hamilton, ON, L8N4L8, Canada.
}

\section{Keywords}

Endscopy, Epistaxis, Nasal packing.

\section{Corresponding author}

${ }^{*}$ Dr. Brihaspati Sigdel

Assoicate Professor

Department of ENT

Gandaki Medical College \& Teaching

Hospital, pokhara, Nepal

Email: brihassig1@gmail.com

\begin{abstract}
Introduction: Epistaxis is a common otolaryngological emergency condition. It occurs due to local and systemic cause. Local cause lies within the nose bleeding either anterior or posterior. Commonest site of bleeding anterior epistaxis is kiesselbach's plexus. In posterior epistaxis, it is difficult to locate bleeding site. Epistaxis is controlled by simply pinching of nose, decongested nasal drop and abgel packing. Some cases become more challenging required nasal packing and arterial ligation.
\end{abstract}

Objectives: To study the epidemiological pattern and management of epistaxis.

Methods: This was a retrospective study on pattern of epistaxis managed at Gandaki Medical College Teaching Hospital over a period from April 2015 to April 2016. Information regarding demographic profile, presentation and management of epistaxis was obtained from the Hospital records, ENT Outpatient clinic, Emergency Department, ENT ward and operation theatre.

Results: A total of 78 cases were managed during study period. There was a significant male preponderance with male to female ratio 1.78:1. Patients' age varied from eight to 80 years with mean age 40.7 years. The peak age of incidence was 21 - 30 years group. Idiopathic nasal bleeding 27 (34.6\%) was commonest followed by nasal trauma 23 $(29.5 \%)$ cases and hypertension $16(20.5 \%)$ cases. Seventeen $(21.8 \%)$ cases managed in day care basis with decongested nasal drop, chemical cautery and abgel packing. Remaining cases required nasal packing and bipolar cautery and other specific form of treatment. Five (6.4\%) cases required sphenopalatine artery ligation with no recurrence of bleeding.

Conclusions: Epistaxis is common ENT emergency. Most common causes are idiopathic followed by nasal trauma and hypertension. Prompt management is instituted according to cases. Most of the cases are managed by non-surgical method.

\section{INTRODCUTION}

Epistaxis remains one of the common ENT emergency in medical practice. Prevalence of epistaxis is aournd 7 - $14 \%$ in general population ${ }^{1,2}$. It may be minor to major 
troublesome bleeding which is life-threatening. Epistaxis is classified either primary or secondary according to causal relation. Anatomically, it can be classified anterior and posterior. Posterior epistaxis is more life threatening than anterior ${ }^{2}$.

Different modaliities are available for treatment of epistaxis. In severe bleeding it starts with initial resuscitation. Assessment was done by taking history and by clinical examination. Different treatment modalities include pinching of nose, chemical cautery, anterior nasal packing, posterior nasal packing etc. Surgical ligation of bleeding vessel may require some cases. Earlier times, either maxillary or external carotid artery ligations were done to control refractory epistaxis. Nowadays after Hopkins rod telescope endoscopic sphenopalatine artery ligation is done which has high success rate ${ }^{3}$.

The objective of this study is to find out causes, site of nose and modality of treatments in our setup.

\section{METHODS}

This is a retrospective study done in patients who presented with nasal bleeding in Department of ENT, Gandaki Medical College Teaching Hospital, Pokhara, Nepal during a period of from April 2015 to April 2016. A total of 78 cases of epistaxis were identified. These patients were received from Emergency Department, Otorhinology OPD, and referral cases from other Departments. Post operative nasal bleeding cases were excluded from study. The information regarding demographics of patients, site of bleeding, management were recorded. Data were collected and calculated SPSS version 21.0.

\section{RESULTS}

This study comprised of 78 cases of epistaxis, who attended the Ear, Nose and Throat, Department of Gandaki Medical College Teaching Hospital, Pokhara, Nepal, between April 2015 and April 2016. Patients varied from eight to 80 years of age with mean age $40.7 \pm 19.77$ years. Males were affected more frequently than females. In this study, 50 cases $(64.1 \%)$ were males and 28 (35.9\%) were females. The male to female ratio was $1.78: 1$.
Table 1: Sex distribution of patients

\begin{tabular}{lcc}
\hline Sex & No of cases & Percentage (\%) \\
Males & 50 & $64.1 \%$ \\
females & 28 & $35.9 \%$ \\
Total & 78 & $100 \%$ \\
\hline
\end{tabular}

Table 2: Age distribution

\begin{tabular}{ccc}
\hline Age group (years) & No of cases & Percentage (\%) \\
$0-10$ & 2 & $2.6 \%$ \\
$11-20$ & 9 & $11.5 \%$ \\
$21-30$ & 21 & $26.9 \%$ \\
$31-40$ & 10 & $12.9 \%$ \\
$41-50$ & 8 & $10.3 \%$ \\
$51-60$ & 12 & $15.3 \%$ \\
$61-70$ & 11 & $14.1 \%$ \\
$71-80$ & 5 & $6.4 \%$ \\
Total & 84 & $100.0 \%$ \\
\hline
\end{tabular}

Age group 21 - 30 was most commonly affected (26.9\%) followed by the age group 51 - 60 years (15.3\%). Idiopathic nasal bleeding $27(34.6 \%)$ was commonest followed by nasal trauma $23(29.5 \%)$ cases and hypertension 16 (16.5\%) cases. Most of cases bleed from unilateral side either left or right in $76 \%$ of cases. Bilateral nasal bleeding most commonly found in most of traumatic cases.

Fig 1: Site of epistaxis

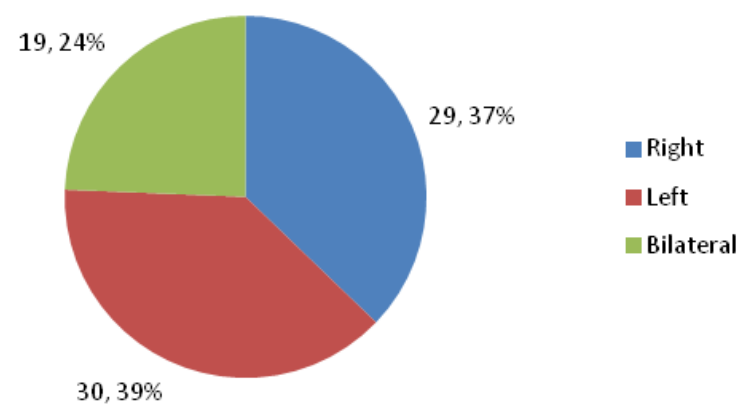

Table 3: Causal factor for epistaxis

\begin{tabular}{lcc}
\hline & No of cases & Percentage (\%) \\
Idiopathic & 27 & $34.6 \%$ \\
Trauma & 23 & $29.4 \%$ \\
Hypertension & 16 & $20.5 \%$ \\
DNS with spur & 6 & $7.8 \%$ \\
Neoplastic (Benign \& malingnant) & 3 & $3.8 \%$ \\
Inflammatory polyp & 2 & $2.6 \%$ \\
Blood dyscrasia & 1 & $1.3 \%$ \\
& 78 & $100 \%$ \\
\hline
\end{tabular}


Table 4: Main modalities of treatment

\begin{tabular}{lcc}
\hline & No of cases & Percentage (\%) \\
Oxymethazoline nasal drop & 4 & $5.2 \%$ \\
Chemical cautery & 5 & $6.4 \%$ \\
Abgel & 8 & $10.2 \%$ \\
Merocele packing & 9 & $11.5 \%$ \\
bipolar cautery & 20 & $25.6 \%$ \\
Sphenopalatine artery ligation & 5 & $6.4 \%$ \\
Nasal bone reduction & 18 & $23.1 \%$ \\
Excsion of tumor & 3 & $3.8 \%$ \\
Septoplasty & 2 & $2.6 \%$ \\
Fess & 2 & $2.6 \%$ \\
Blood transfusion & 2 & $2.6 \%$ \\
& 78 & $100 \%$ \\
\hline
\end{tabular}

\section{DISCUSSION}

Epistaxis is a common otorhinolaryngological emergency. It ranges from little spot bleeding to a life threatening condition. It occurs in any age group from Pedatrics to adult. In our study, it occur from eight years of age to 80 years old patients. Etiology is different for different age groups. Epistaxis is common in all age groups.

Common local cause include trauma, tumor of nasal cavity, nose pricking, foreign body etc. systemic disease also present with epistaxis in hypertension, liver disease, bleeding disorder, liver disease, renal failure. Mean age of epistaxis found in our study was 40.7 years, similar finding found in a study by Akinpelu et $a l^{4}$. Epistaxis was found more common in males, with a male to female ratio of $1.78: 1^{5,6,7}$. The higher incidence in males may be due to as increased exposure to trauma, physical assault and other injures. Women have less bleeding may be due to effect of estrogen ${ }^{8}$.

In our study commonest etiological factor was idiopathic (34.5\%), followed by the trauma (29.4\%) and hypertension (20.5\%), which is similar finding Iseh KR et $a l^{9}$, Varsney et $a l^{10}$. Bhaumik $\mathrm{N}$ et $a l^{8}$ and Hanif $\mathrm{M}$ et $a l^{11}$ found that hypertension followed by trauma are the common causes of epistaxis. Unilateral bleeding occur in $76 \%$ of cases, either left or right. It signifies probability of local causes in idiopathic epistaxis.

Trauma was second most common cause of epistaxis in our study but Shresta I et $a l^{12}$ showed trauma is most common cause. Trauma is more common in younger age group. Young people are the most active in the population so are more vulnerable to trauma from nose picking, fights, road traffic accidents, fall injury and physical assault. Out of 23 nasal trauma cases, 16 (69.9\%) cases require reduction of nasal bone. Two (8.6\%) cases with open reduction and remaining five $(21.7 \%)$ cases treated with conservative treatment.

Hypertension is common above 40 years of age. Hypertension being the third commonest cause of epistaxis in our study but first common cause in study by Henif $\mathrm{M}$ et $a{ }^{11}$. Most of the large studies have failed to show a causal relationship between hypertension and epistaxis ${ }^{2}$. It signifies the poor blood pressure control. Strict regular blood pressure checkup and control must be emphasized.

Treatment of epistaxis range from observation to medical or surgical treatment. In our study $21.8 \%$ of cases epistaxsis controlled by decongested (Oxymethazoline) nasal drop, chemical cautery and abgel. We feel treatment of epistaxis depends on amount and site of bleeding. It is better to observe overnight such patient in hospital. Most of case, we first do anterior nasal packing either ribbon gauze or merocele. After arresting active bleed, with in next 48 hour, we do endoscopy of nose by hopkin telescope 0 or 30 degree. If bleeding site seen, we do bipolar cautery to stop bleeding. It is effective method of treatment $\mathrm{t}^{13,14,16}$. Cauterization of bleeding vesel done in $25.5 \%$ cases. In cases, where bleeding point uncertain, but bleeding present, those cases were managed with sphenopalatine artery ligation. In five (6.4\%) cases, sphenopalatine artery ligation was done in our study. Ninety percent of the nasal mucosa received its blood supply via the sphenopalatine artery ${ }^{17}$. It is very effective method of surgical treatment with high success rate. It overall reduces hospital admission and cost of treatment ${ }^{18}$. No rebleeding occur in our study after artery ligation

In bleeding mass, we should think of nasal benign and malignant lesion. Endoscopic sinus surgery was done in $6.4 \%$ of cases, of them two hemangioma, one inverted papilloma and two nasal polyposis. The need for resuscitation in cases of severe epistaxis should be emphasized to prevent hypovolemic shock and fatal outcome. Prompt evaluation of quantity of blood loss and timely intervention is crucial in the management of epistaxis. There may be the need for blood transfusion. Two cases needed blood transfusion. 


\section{CONCLUSIONS}

Epistaxis is common otolaryngological emergencies. Most common causes are idiopathic followed by nasal trauma and hypertension. Careful history and nose examination is essential to make diagnosis. Prompt management is instituted according to cases. Treatment depends on amount and site of bleeding. Most of the cases are managed by non-surgical method.

\section{Funding}

No funding sources

\section{Conflict of Interest}

None

\section{REFERENCES}

1. Wormald PJ. Epistaxis. Byron and Bailey's Head and Neck Surgery Otolaryngology. 4th ed. Philadelphia: Lippincott Williams and Wilkins; 2006. p505-14.

2. McGarry. Epistaxis. Scott-Brown's otorhinolarngology, Head and Neck surgery. 7th ed. London: Edward Arnold Publishers; 2008. p.1596-1608.

3. Snyderman CH, Goldman SA, Carrau RL, Ferguson BJ, Gandis JR. Endoscopic sphenopalatine artery ligation is an effective method of treatment for posterior epistaxis. American Journal of Rhinology. 1999 MarApr; 13(2): 137-40.

4. Akinpelu OV, Amusa YB, Eziyi JA, Nwawolo CC. A retrospective analysis of aetiology and management of epistaxis in a South-Western Nigerian Teaching Hospital. West Afr J Med. 2009 May; 28(3): 165-8.

5. Lewandowski AS, Sliwińska-Kowalska M. Occurrence of epistaxis in relation to seasonal factors. Wiad Lek. 1993 Aug; 46(15-16): 597-602.

6. Padgham N. Epistaxis: Anatomical and clinical correlates. Journal of Laryngology and Otology. 1990; 104: 308-11.

7. Kodiya AM, Labaran LS, Musa E. Epistaxis in Kaduna, Nigeria: A review of 101 cases. African Health Sciences. 2012; 12(4): 479-82.
8. Bhaumik N, Sukla B, Das B, Dey D, Nandi TK. Pattern of Epistaxis of Patients Attending in A Tertiary Care Hospital of Tripura, North-Eastern Region of India. IOSR Journal of Dental and Medical Sciences. 2016 May; 15( 5) :42-44.

9. Iseh KR, Muhammad Z. Pattern of Epistaxis in Sokoto, Nigeria: a review of 72 cases. Ann Afr Med. 2008; 7(3): 107-11.

10. Varshney S, Saxena RK. Epistaxis: A retrospective clinical study. Indian J Otolaryngol Head Neck Surg. 2005; 57(2): 125-9.

11. Hanif M, Rizwan M, Rabbani MZ, Chaudhary MA. Common causes of epistaxis: A two years' experience at Rawalpindi General Hospital. Journal of Surgery Pakistan. 2001; 6(2): 2-3.

12. Shrestha I, Pokharel M, Shrestha BL, Dhakal A, Amatya RCM. Evaluation of aetiology of epistaxis and its management in Dhulikhel Hospital. Kathmandu Univ Med J. 2015; 49(1): 49-55.

13. Daudia A, Jaiswal V, Jones NS. Guidelines for the management of idiopathic epistaxis in adults: How we do it. Clinical Otolaryngology. 2008; 33: 607-628.

14. Rodney JS: Epistaxis: A clinical experience. New England Journal of Medicine. 2009; 360: 784-9.

16. Basheer NK, Jaya C, Sabir VT. Epistaxis: Etiological profile and treatment outcome in a Teaching Hospital in South India. International Journal of Otorhinolaryngology and Head and Neck Surgery. 2017 Oct; 3(4): 878-884.

17. Loughran S, Hilmi O, McGarry GW. Endoscopic sphenopalatine artery ligation-when, why and how to do it. An online video tutorial. Clin Otolaryngol. 2005; (30): 539-43.

18. Barnes ML, White PS. Epistaxis: A contemporary evidence based Approach. Otolaryngol Clin N Am. 2012; (45): 1005-1017 